\title{
Overuse Injuries of Finnish Elite Junior Ice Hockey Players. Prospective Online Survey
}

\section{Listola, Joni}

2013

Listola , J , Ruismäki , H , Valtonen , J , Welling , J \& Hakkarainen , H 2013 , ' Overuse

Injuries of Finnish Elite Junior Ice Hockey Players. Prospective Online Survey ' , The

European Journal of Social \& Behavioural Sciences , vol. 7 , pp. 1203-1212 . https://doi.org/10.15405/ejsbs.100

http://hdl.handle.net/10138/233047

https://doi.org/10.15405/ejsbs.100

cc_by_nc_nd

publishedVersion

Downloaded from Helda, University of Helsinki institutional repository.

This is an electronic reprint of the original article.

This reprint may differ from the original in pagination and typographic detail.

Please cite the original version. 


\title{
The European Journal of Social \& Behavioural Sciences (EJSBS)
}

\section{Overuse Injuries of Finnish Elite Junior Ice Hockey Players. Prospective Online Survey}

\author{
Joni Listola $^{\mathrm{a} *}$, Heikki Ruismäki ${ }^{\mathrm{b}}$, Juha Valtonen ${ }^{\mathrm{b}}$, Jesse Welling $^{\mathrm{c}}$, Harri Hakkarainen ${ }^{\mathrm{d}}$ \\ ${ }^{a}$ University of Eastern Finland \\ ${ }^{b}$ University of Helsinki, Finland \\ ${ }^{c}$ Rauma Lukko Hockey, Finland \\ ${ }^{d}$ National Olympic Committee, Finland
}

http://dx.doi.org/10.15405/ejsbs.100

\begin{abstract}
Frequent forceful impacts, the unpredictable nature of the game, the long sticks and the sharp blades of the skates as well as high velocity of skating and shooting the puck make ice hockey an injury-prone sport. Most of the previous ice hockey injury studies have focused on traumatic injuries. In team sports, absence of one player may affect the team's performance and chances of winning. This fact might create pressure for a player to decide to compete while injured or ill. The purpose of the study was to define the number, type, and anatomic location of overuse injuries in the high level Junior A and B (15-19-year-old) ice hockey players, and whether players report the injuries to coaching and medical staff. Players self-reported the injury data via online survey. The data was collected between September 2009 and March 2010. Out of 55 subjects, 33 players (62\%) were injured. Of all injuries, $70.4 \%$ (45 injuries) were traumatic and 69.6\% (19 injuries) were overuse injuries. Players reported $95 \%$ of the injuries to coaching staff and they reported $75 \%$ of the injuries to medical staff. Injuries that were not reported to coaching or medical staff were minor injuries. The estimated average probability of player sustaining at least one injury during the season was $62.2 \%$ (95\% CI 0.49-0.75). Hip/groin was the most common site for overuse injury (7 injuries, $36.8 \%$ of all overuse injuries). Therefore, injury prevention focus should be placed on reducing the number of muscle sprains and especially hip/groin injuries. More knowledge is needed about the modifiable risk factors of these injuries. Injuries that were not reported to coaching or medical staff were all minor injuries.
\end{abstract}

(C) 2013 Published by C-crcs. Peer-review under responsibility of Editor or Guest Editor of the EJSBS.

Keywords: sports injuries; ice hockey; overuse injuries; repetitive stress injuries

* Joni J. Listola Tel.: +358-44-210-5032

E-mail address: joni.listola@gmail.com

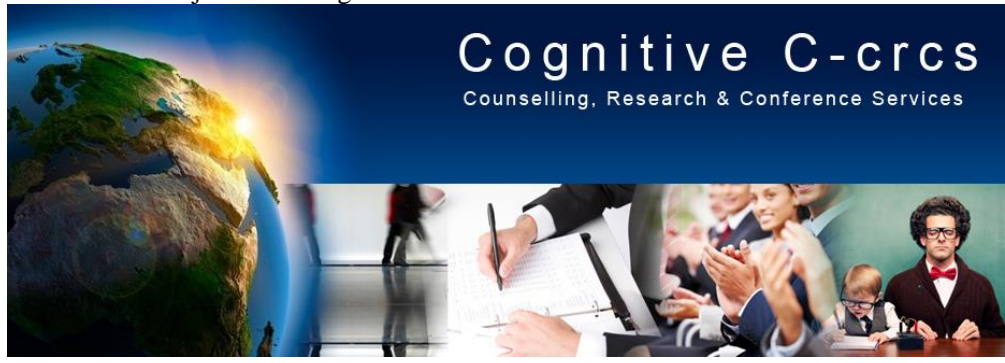




\section{Introduction}

Frequent forceful impacts, the unpredictable nature of the game, the long sticks and sharp blades of the skates as well as the high velocity of skating and shooting the puck make ice hockey an injury-prone sport. The risk of injury inreases with age and level of play (Tegner \& Lorentzon, 1991; LaPrade et al., 1995; Tator et al., 1997; Mölsä et al., 2000; 2003; Goodman et al., 2001; Biasca et al., 2002; Wennberg \& Tator, 2003). In addition, players are bigger and stronger than in the past (Cox, 1995; Montgomery, 2006). Possible long-term implications for athletes and significant medical and economic cost are associated with sports injuries. It is important to establish injury profiles in contact sports such as ice hockey and facilitate implementation of injury reduction strategies.

Traumatic injuries in hockey are usually the result of contact to other player, boards, ice surface, or equipment (Pelletier et al., 1993; Mölsä et al., 2000; Flik et al., 2005; Agel et al., 2007). The methods to reduce these injuries is mainly limited to rule changes, the development of better protective equipment or changes in the board materials. However, developing proper strength and conditioning strategies might have a direct effect on the prevalence of overuse injuries and muscle strains/sprains in ice hockey. Most of the ice hockey injury studies have focused only on investigating traumatic injuries. It is essential to clarify the incidence of overuse injuries and the body parts most vulnerable to overuse injuries before the initiation of prevention strategies.

Culture of contact sports does not support self-reporting by athletes of minor injuries to coaches and medical staff as it may affect perception of athlete's "toughness" (Loland et al., 2006). Also, in team sports absence of one player may affect the team's performance and chances of winning. This fact might create pressure for a player to decide to compete while injured or ill.

The purpose of this study was to define the number, type, and anatomic location of overuse injuries in highest level of junior A- and B-level players over one competitive ice hockey season. In addition, information on whether players reported the injuries to medical staff was gathered. Due to the high incidence of ice hockey-related injuries, focus should be placed on possible injury reduction strategies. Data obtained in this study may be used in developing future coaching and injury prevention strategies.

\section{Background}

Skating, handling the stick, body checking, passing, blocking, and shooting the puck are the essential skills of a hockey player. The game of ice hockey is fast paced and game situations on the ice change rapidly. Players quickly accelerate, turn, and brake depending on the game situations and location of the puck. Adult players may reach a skating speed of over $50 \mathrm{~km} / \mathrm{h}$ (Sim et al., 1987). The term body checking is used to describe players' powerful contact with opposing players by using shoulders or hips in order obtain the possession of the puck. Body checking is allowed in men's ice hockey and is frequent during the games. Due to the fast pace and frequent contacts to opposing players, ice hockey may be considered as an aggressive team sport.

\subsection{Traumatic injuries}

Traumatic injuries usually occur in the presence of external force applied to the body exceeding its ability to maintain its structural and/or functional integrity resulting in tissue damage. Injury may occur in contact with an opposing player, the ice surface, the boards, a puck or stick. Acute injuries are usually unpredictable and the injury mechanism may be defined (Fuller et al., 2006).

\subsection{Overuse injuries}

Overuse injuries may be classified into two main categories. The first category is the low-force repetitive stress injuries causing micro trauma typically seen in endurance sports such as running. The second category of overuse injuries is "overstress" injuries that usually occur during rapid body movement when high force is applied suddenly resulting in tissue damage. These types of injuries are typical in fast-paced, power sports as well in most team sports that require sudden, powerful movements from athletes (Karpakka \& Kujala; 1999). No clear definition for overuse injuries exists (Parkkari et al., 2001). Different definitions affect incidence rates. 
Overuse injuries usually result from continued cumulative trauma over weeks or months. The onset of symptoms may be gradual resulting in subtle increasing pain during athletic activities. Although the severity of overuse injuries is not usually as great as in traumatic injuries, they may cause substantial inconvenience and discomfort to athlete due to chronic and recurring nature (Parkkari et al., 2004 ).

The majority of the ice hockey injuries are acute injuries, with the most common injury mechanism being body checking or another form of contact/collision (Pelletier et al., 1993; Mölsä et al., 2000; Flik et al., 2005; Agel et al., 2007). Shoulder injuries, fractures in the upper extremities, knee injuries, injuries to the head and face region, knee injuries, muscle sprains/strains, and lacerations are the most common injuries in ice hockey (Sim et al., 1987, Daly et al., 1990; Biasca et al., 1995). Mölsä has reported similar results from the Finnish hockey leagues (Mölsä et al., 1997, 2000, 2003 ).

Injuries are far more likely to occur during games than in practice situations. Flik et al. (2005) reported a 6,3\% greater risk of becoming injured during games than in practice situations. Injury risk increases as players increase in size and velocity (Tegner \& Lorentzon, 1991; LaPrade et al., 1995; Tator et al. 1997; Mölsä et al., 2000, 2003; Goodman et al., 2001; Biasca et al., 2002; Wennberg \& Tator, 2003).

\section{Purpose of the Study}

The purpose of this study was to define the number, type, and anatomic location of overuse injuries at the highest level of junior A- and B-level players over one competitive ice hockey season. In addition, information on whether players reported the injuries to medical staff was gathered. Due to the high incidence of ice hockey-related injuries, the focus should be on possible injury reduction strategies. Data obtained in this study may be used in developing ice hockey coaching and future injury prevention strategies.

\section{Research questions}

What is the number, type and anatomic location of overuse injuries in Junior A- and B-level players over a competitive hockey season? Do players report the injuries to coaching or medical staff?

\section{Methods}

\subsection{Target population}

Subjects (N=53) were 15-19-year-old players from the three highest level Junior A-teams and the two highest level Junior B-teams of the Finnish league. Injury data was collected prospectively using an online survey between September 2009 and March 2010. Prior to the study, all players completed a questionnaire providing information about their background, sports participation, and previous injuries.

The subjects' average age, height and weight are displayed in table 1 . Twenty-five (47\%) of the subjects were forwards, $20(38 \%)$ defenders, and $8(15 \%)$ goalies. Forty-seven (89\%) players reported having had previous ice hockey-related traumatic injury and $44(83 \%)$ players reported having had previous ice hockey-related overuse injury. Forty-eight $(90.5 \%)$ players reported having had previous ice hockey or other organized athletic activityrelated traumatic injury and $46(86.7 \%)$ players reported previous overuse injury. The most common reported injuries were muscle and tendon strains/sprains, ligament injuries and lower back pain.

Table 1. Subject characteristics $(\mathrm{n}=53)$

\begin{tabular}{llll}
\hline & Average & SD & Range \\
\hline Age (years) & 17.3 & \pm 1.17 & $15-19$ \\
Height (cm) & 179.8 & \pm 5.11 & $169-193$ \\
Weight (kg) & 77.3 & \pm 6.61 & $63-92$ \\
\hline
\end{tabular}

$\mathrm{SD}=($ standard deviation $), \mathrm{cm}=$ centimeters, $\mathrm{kg}=$ kilograms 


\subsection{Data collection methods}

Data was collected between September 2009 and March 2010. Injuries and practice/game participation was recorded during the 2009-2010 competitive season. Team coaches were responsible for collecting game and practice information.Participating players self-reported the injuries using an online survey (Webropol 1.0 online survey and analysis software). A reminder to report the injuries and fill out the survey was sent bi-weekly via email. A direct link to the survey was attached to each reminder email. Injury data was collected anonymously; each player had been given a personal four-digit code that was used during the remainder of the study. The bi-weekly survey included questions on the onset of new injuries, time of injury, where the injury occurred, whether the injury was a traumatic or overuse injury, the injured body part, type of injury, and possible diagnosis. Information was also gathered about whether the injury prevented full participation in practice or games, days missed of full participation in practice or games. Furthermore, information on whether the player contacted a physician or physical therapist regarding the injury, and was the coach informed about the injury was also collected. The survey had multiple options for responses and a player could type additional information in a marked field.

Altogether 99 players completed the injury survey during the study. Only players who had completed the injury survey at least 10 times over the course of the study were included as subjects in the final study. Thus, information from an individual player was obtained at least once a month. Fifty-three players completed the survey 10 or more times.

The Junior A-team competitive season commences in September and ends in February the following year. The total number of games depends on the number of practice games and final placing in the standings. On the highest level of Junior A-team hockey in Finland during the 2009-2010 season, there were 15 teams in the league, which played three times against each other for a total of 42 games. During the 2009-2010 Junior B-team competitive season, 14 teams played twice against each other over the course of the season for a total of 26 games.

The Junior A-teams play 2-3 games a week and Junior B-teams play 2 games per week on average. During the competitive season, the Junior A-teams practice 4 times per week on average. An on-ice practice session lasts 90 minutes on average and off-ice practice sessions 60-90 minutes. In addition, on game days most teams have an onice practice session in the morning. Junior B-teams practice calendar is similar to that of Junior A-teams, although fewer on-ice practice sessions might be held on game day mornings.

\section{Findings}

All self-reported traumatic or overuse injuries occurring in on-ice game/practice situation or off-ice training were recorded as injuries. Altogether, 64 injuries occurred during the study (1.21 injuries per player). 33 (62\%) out of 53 players were injured (figure 1.).

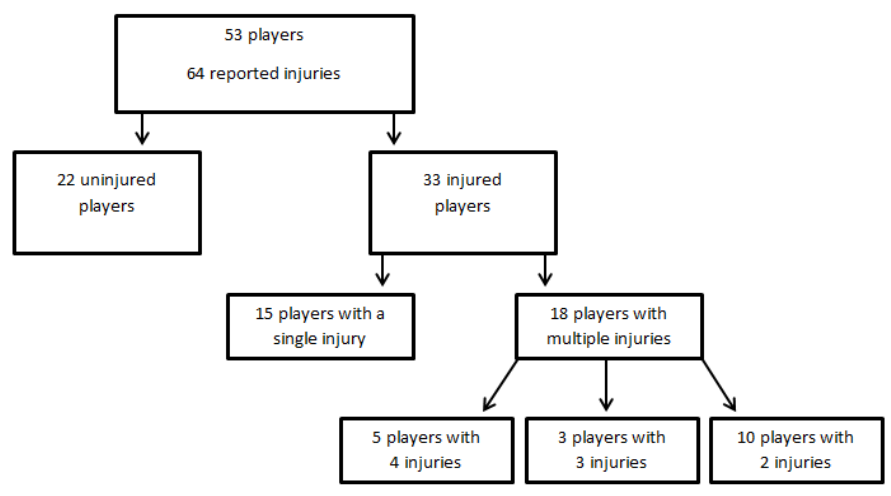

Fig.1. Incidence of injury during one season 
Forty-five $(70.3 \%)$ of injuries were traumatic and 19 (29.6\%) of injuries were overuse injuries. Twenty-three $(69.6 \%)$ of injured players had sustained only a traumatic injury and $3(9 \%)$ players sustained only overuse injury. Six (18\%) players sustained both traumatic and overuse injuries.

Twenty forwards $(80 \%)$ were injured and 11 of the defenders $(55 \%)$ were injured. Two $(25 \%)$ of the eight goalies were injured as well. Of all the injuries, 55\% (35 injuries) affected the forwards (28 traumatic injuries and 9 overuse injuries). Of all injuries, 40.6\%, 26 injuries occurred in game situations (figure 2.) On-ice practice sessions were the second most common occasion for injury (31.3\% of all injuries, 20 injuries). For 14 injuries (21.8\%), the player was not able to identify the occasion of the injury or did not report it.

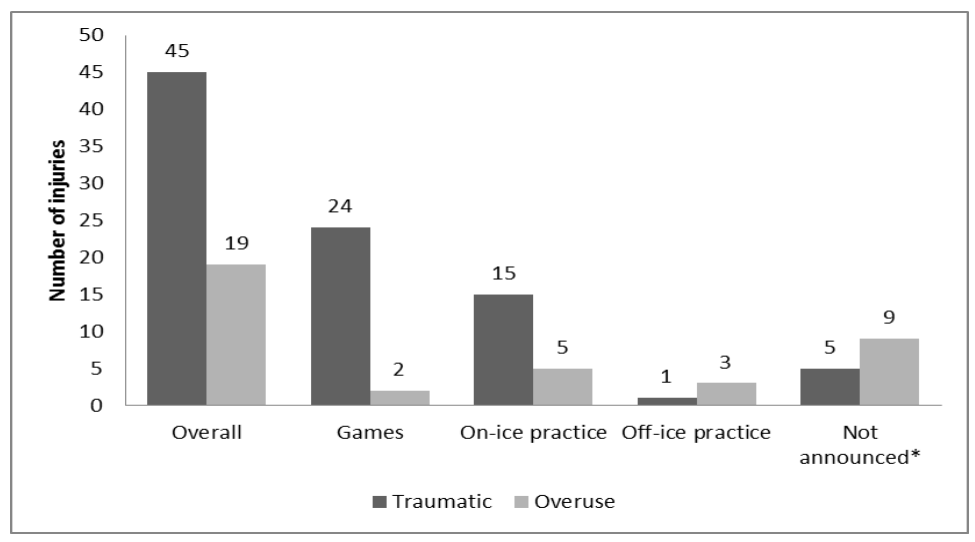

*Player replied "Not sure"(7), "Other"(2) or did not report (5)

Fig. 2. Number of traumatic and overuse injuries in game versus practice

The estimated average probability of any player sustaining at least one injury over the course of the season was $62.2 \%$ (95\% CI 0, 49-0.75). Out of 33 injured players, 18 players had multiple injuries. The probability of subsequent injury during the season was $54.5 \%$ (95\% CI 0, 38-0.72). Nineteen players (36\%) were injured during games; altogether 26 injuries occurred during games.

Out of 64 injuries, $62.5 \%$ (40 injuries) prevented players from full participation in the game or practice activities. Twenty-four injuries (37.5\%) did not limit a player from full participation in game or practice activities. Twentyseven players $(50.9 \%)$ sustained at least one injury that prevented them from full participation in game or practice activities. The estimated average probability of sustaining at least one injury that prevented a player from full participation in a game or practice activity over the course of the season was $50.9 \%$ (95\% CI $0,41-0,61)$. Of these injuries, $67.5 \%$ (27 injuries) were traumatic and 32.5\% (13 injuries) were overuse injuries.

The most commonly injured body parts were the shoulder (13 injuries; $20.3 \%$ of all injuries) and the groin/hip region (13 injuries, $20.3 \%$ of all injuries). Thirty-two injuries (50\%) were located in the lower extremities. 8 injuries $(12.5 \%)$ were in the upper leg area (front, back, inner or outer thigh). Twenty-one injuries (32.8\%) were located in the upper extremities. The number of injuries by body region is reported in table 2 .

Muscle and tendon injuries were the most common type of injury (27 injuries, $42.2 \%$ of all injuries). Sixteen injuries $(25 \%)$ were muscle related (rupture, tear, strain, cramp) and 11 injuries (17.2\%) tendon related (rupture, tendinosis ). Thirteen injuries (20.3\%) were contusions or lacerations.

\subsection{Overuse injuries}

Overuse injuries represented 29.6\% (19 injuries) of all injuries. Ten players sustained an overuse injury during the study. The estimated average probability of sustaining at least one overuse injury during the season was $18.8 \%$ 
(95\% CI 0.13-0,24). Of all overuse injuries, 63\% (12 injuries) were located in the lower extremities (table 2.). The hip/groin was the most common body part affected by an overuse injury ( 7 injuries, $36.8 \%$ of all overuse injuries). The majority of overuse injuries were muscle injuries ( 6 injuries, $31,5 \%$ of all overuse injuries) and tendon injuries ( 5 injuries, 26.3\%). In five of the overuse injury cases, the type of injury could not be identified with the information provided by the player (i.e., "overuse injury in the calf/shin"). Two of the overuse injuries (11\%) were abrasions of the skin sustained in running. Out of eight overuse injury cases, $(42.1 \%)$, the player was not able to or did not report the occasion on which the injury had occurred. An on-ice practice session was the occasion for five (26.3\%) of the overuse injury cases and four of the cases occurred during the off-ice training session.

Furthermore, $63.2 \%$ (12 injuries) of all overuse injuries prevented full participation in games or practice sessions. Two of the overuse injuries that required the longest period before the player could return to full participation in the games or practice (15-30 days) were tendinitis in the ankle and an inflamed hip flexor. Three overuse injuries required 8-14 days recovery time, and three overuse injuries required 1-3 days of down time before the player could return to full participation. Four overuse injuries required 4-7 days break from full participation in game or practice activities.

Table 2. Number of injuries and percentage of all injuries

\begin{tabular}{|c|c|c|c|}
\hline Injury location & Traumatic & Overuse & Overall \\
\hline Lower limbs & $20(31 \%)$ & $12(19 \%)$ & $32(50 \%)$ \\
\hline Hip/groin & $6(9 \%)$ & $7(11 \%)$ & $13(20 \%)$ \\
\hline Thigh & $6(9 \%)$ & $2(3 \%)$ & $8(13 \%)$ \\
\hline Knee & $3(5 \%)$ & & $3(5 \%)$ \\
\hline Lower leg/Achilles & $1(2 \%)$ & $1(2 \%)$ & $2(3 \%)$ \\
\hline Ankle & $3(5 \%)$ & $2(3 \%)$ & $5(8 \%)$ \\
\hline Foot/toe & $1(2 \%)$ & & $1(2 \%)$ \\
\hline Upper limbs & $16(25 \%)$ & $5(8 \%)$ & $21(33 \%)$ \\
\hline Shoulder/clavicula & $10(16 \%)$ & $3(5 \%)$ & $13(2 \%)$ \\
\hline Elbow & $1(2 \%)$ & & $1(2 \%)$ \\
\hline Wrist & $3(5 \%)$ & $2(3 \%)$ & $5(8 \%)$ \\
\hline Hand/fingers & $2(3 \%)$ & & $2(3 \%)$ \\
\hline Trunk & $3(5 \%)$ & $2(3 \%)$ & $5(8 \%)$ \\
\hline Upper back/sternum & $2(3 \%)$ & & $2(3 \%)$ \\
\hline Lower back/pelvis & $1(2 \%)$ & $2(3 \%)$ & $3(5 \%)$ \\
\hline Head and neck & $6(9 \%)$ & & $6(9 \%)$ \\
\hline Head/face & $5(8 \%)$ & & $5(8 \%)$ \\
\hline Neck/cervical spine & $1(2 \%)$ & & $1(2 \%)$ \\
\hline Overall & $45(70 \%)$ & $19(30 \%)$ & 64 \\
\hline
\end{tabular}

\subsection{Severity of injuries}

Out of 64 injuries, 40 injuries $(62.5 \%)$ prevented full participation in games or practice, although most of the injuries were mild. Thirty-two per cent of these injuries (12 injuries), required a 1-3-day absence from full 
participation (figure 3.) Five injuries (13\%) required a 4-7-day absence from full participation. Eleven injuries (29\%) required an 8-14-day absence from full participation and 7 injuries (18\%) required a 15-30-day absence from full participation. Three injuries (8\%) were considered severe (with an over-30-day absence from full participation). A fracture of the wrist and two cases of dislocations (knee, shoulder) were the most severe injuries. Two players reported that the injuries prevented full participation in games or practices, but they did not report the number of days missed.

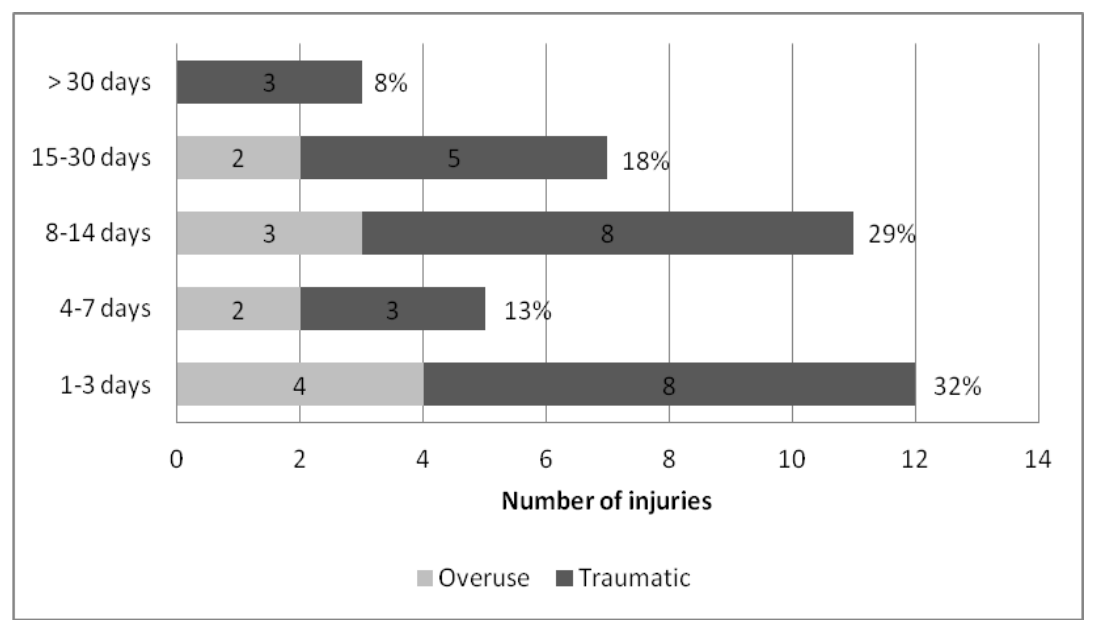

Fig.3. Severity of injuries that prevented full participation to games or practice sessions ( $\mathrm{n}=40$ )

\subsection{Reporting of injuries}

In 23 of the 40 injury cases $(57.5 \%)$ that prevented full participation in games or practices, the player had contacted a physician. In seven cases, the player had not contacted a physician, but had contacted a physical therapist instead. Thus, in 30 injury cases $(70 \%)$ a player had contacted an allied health care professional. In 29 of these cases, the player reported receiving clear instructions regarding their injury from physician or physical therapist. In 8 cases $(20 \%)$ both the physician and physical therapist were contacted. In 10 cases in which the player had not contacted a member of the medical staff, all but one injury was reported as minor and required only 1-3 days absence from full participation in games or practices. Two of the most common of these injuries were abrasions ( 3 injuries) and contusions ( 3 injuries). Overall, in 38 of the 40 injury cases (95\%), the team coach was informed about the injury. The two injury cases that prevented full participation, but were not reported to the coach were minor (abrasion of the skin, bruised shoulder).

\section{Discussion}

The estimated average probability of any player sustaining at least one injury during one season was $62.2 \%$ (95\% CI 0.49-0.75). The information may be valuable to coaches, parents, and medical professionals in planning medical resources. Eighteen of the 33 injured players had multiple injuries during the season. The estimated average probability of sustaining a subsequent injury during one season was $54.5 \%$ (95\% CI 0.38-0.72). Information on subsequent injuries is important for coaches and medical personnel. However, risk of subsequent injury is rarely discussed in the sports injury literature.

Overuse injuries presented $29.6 \%$ of all the injuries, which is a larger portion than has been reported in previous studies (Daly et al., 1990; Stuart \& Smith, 1995; Pinto et al., 1999; Flik et al., 2005; Rishiraj et al., 2009). Although, in their causal analysis on intercollegiate hockey injuries, Ferrara \& Schurr (1999) reported 45 overuse or noncontact injuries out of all 113 injuries (40\%). Different injury definitions used in various studies may have an effect 
on the prevalence of overuse injuries reported. In addition, self-reporting may be biased on over reporting (Bailey et al., 2010).

Twelve overuse injuries (63\% of all overuse injuries) were located in the lower extrimities. Hip/groin was the most common site for overuse injury ( 7 injuries, $36.8 \%$ of all overuse injuries). Mechanics of skating stride make muscles of the hip and thigh susceptible to soft tissue injury. Tyler et al. (2001) reported adductor muscle weakness as a risk factor for adductor muscle strain. Tyler et al. (2002) also reported a preseason exercise progran to be effective in preventing adductor muscle strains in professional ice hockey players. Emery \& Meeuwisse (2001) did not find peak isometric adductor torque or total abduction flexibility to be predictor for groin injury in professional players, however, in their research low levels of off-season hockey specific training and previous injury were defined as risk factor for groin injury. Screening and identifying underlying muscle imbalances of symptomatic and asymptomatic players and designing proper exercise programs based on the evaluation might have direct effect on non-contact soft tissue injuries. Neuromuscular training has been effective in reducing non-contact injuries in women's floorball (Pasanen et al., 2008), Military personnel (Parkkari et al., 2011), women's handball (Myklebust et al., 2007), and men's basketball (Longo et. al., 2012).

In seven injury cases, the players were not able to distinguish whether an injury was a traumatic or an overuse injury. Five of these injuries were later classified as an overuse injury by a sport physician that specialized in treating hockey injuries (based on the injury information provided by the player in the survey). In these cases, players were not able to define the occasion on which the injury had occurred. For traumatic injuries, usually a specific, identifiable event has been defined (Fuller et al., 2006).

Not reporting of injuries and playing injured might be considered desirable trait of many contact sports (Loland et al., 2006). In this study, 95\% the injuries were reported to coaching staff and $75 \%$ of injuries were reported to medical staff. Injuries that were not reported to coaching or medical staff were minor injuries. However, failing to report more serious injuries (i.e., concussion) and competing injured or ill might have detrimental consequences on the current and future health of the player.

Overuse injuries caused mostly a short-term absence from full participation in games or practices (figure 3.). However, five of the overuse injuries recurred during the follow-up (recurred within two months of the onset of the first injury). The chronic nature of overuse injuries might cause a long-term hindrance to athletes.

\subsection{Limitations}

Players self-reported the injuries via an online survey, so the possible limitations should be acknowledged. Selfreporting and players' own interpretation may not provide the true diagnosis of the injury. In studies in which injuries are diagnosed by a team doctor or other health care professional, accurate information on diagnosis, injury type and mechanism is provided. In this study, the final diagnosis was reported only for injuries that required evaluation by physician. In seven injury cases, the player was not able to report whether the injury mechanism was traumatic or overuse injury. Final conclusions and classifications were conducted by a sports doctor experienced in treating ice hockey injuries, based on the injury information provided by the player. In a few cases, the injury information was limited, so the possibility of misclassification cannot be excluded. On the other hand, self-reporting brings out even minor injuries. In studies in which the definition of an injury is based on the number of days missed of game/practice participation might not record the minor injuries such as abrasions or contusions. Thus, overreporting of minor injuries must be considered. Furthermore, self-reporting is subject to the subjects' differences in pain tolerance and opinion. (Bailey et al., 2010).

It is possible that this single-season injury study underestimates the true scope of certain injuries. For example, not a single concussion case was reported during the season and only three cases of lower back soreness were reported. However, these types of injuries are common in ice hockey. Twenty-one per cent (11 players) reported a prior concussion and 55\% (29 players) reported a prior case of lower back discomfort/injury in the background questionnaire prior to the study. 


\section{Conclusions}

The estimated average probability of player sustaining at least one injury during the season was $62.2 \%$ (95\% CI 0.49-0.75). Of all injuries ( $n=64), 70.4 \%$ (45 injuries) were traumatic and 69.6\% (19 injuries) were overuse injuries. Lower extremity injuries represented majority of all injuries $(50 \%)$. Hip/groin was the most common site for overuse injury ( 7 injuries, $36.8 \%$ of all overuse injuries). $20 \%$ of all traumatic injuries were muscle sprains and strains (9 injuries). Overuse injuries were mostly in muscle (31.5\%, 6 injuries) and in tendons (26.3\%, 5 injuries). Therefore, injury prevention should focus on reducing the number of muscle sprains and especially hip/groin injuries. More knowledge is needed about the modifiable risk factors of these injuries. Injuries that were not reported to coaching or medical staff were minor injuries.

\section{References}

Agel, J., Dompier, T.P., Randall D., Stephen, M.W. (2007). Descriptive epidemiology of collegiate men's ice hockey injuries: National Collegiate Athletic Association Injury Surveillance System, 1988-1989 through 2003-2004. Journal of Athletic Training,42, $241-248$.

Bailey, S., Scase, E., Heynen, M., Magarey, M.E. (2010). A Review of sports injury data collection literature and recommendations for future research. The Internet Journal of Allied Health Sciences and Practice, 8, 1-14.

Biasca N., Simmen, H.P., Bartolozzi, A.R., Trentz, O. (1995). Review of typical ice hockey injuries. Survey of the North American NHL and Hockey Canada versus European Leagues. Unfallchirurg, 98, 283-288.

Biasca, N., Wirth, S., Tegner, Y. (2002). The avoidability of head and neck injuries in ice hockey: an historical review. British Journal of Sports Medicine, 36, 410-427.

Cox, M.H., Miles, D.S., Verde, T.J., Rhodes, E.C. (1995). Applied physiology of ice hockey. Sports Medicine, 3, $184-201$.

Daly, P.J., Sim, H.F., Simonet, W.T. (1990). Ice hockey injuries. Sports Medicine, 10, 122-131.

Emery, C.A., Meeuwisse, W.H. (2001). Risk factors for groin injuries in hockey. Medicine and Science of Sports and Exercise, 33, 1423-1433.

Ferrara, M.S., Schurr, K.T. (1999). Intercolligiate ice hockey injuries: A causal analysis. Clinical Journal of Sports Medicine, 9, $30-33$.

Flik, K., Lyman, S., Marx, R.G. (2005). American collegiate men's ice hockey: an analysis of injuries. American Journal of Sports Medicine, 33, 183-187.

Fuller, C.,W., Ekstrand, J., Junge, A., Andersen, T.E., Bahr, R., Dvorak, J., Hägglund, M., McCrory, P., Meeuwisse, W.H. (2006). Consensus statement on injury definitions and data collection procedures in studies of football (soccer) injuries. Clinical Journal of Sports Medicine, 16, 97-106.

Goodman, D., Gaetz, M., Meichenbaum, D. (2001) Concussion in hockey: there is cause for concern. Medicine and Science in Sports and Exercise, 33, 2004-2009.

Karpakka J \& Kujala U. (1999). Rasitusvammat. In I. Vuori, \& S. Taimela. (Eds.), Liikuntalääketiede (pp. 363-383.). Helsinki: Kustannus Oy Duodecim.

LaPrade, R.F., Burnett, Q.M., Zarzour, R., Moss, R. (1995). The effect of the mandatory use of face masks on facial lacerations and head and neck injuries in ice hockey. A prospective study. American Journal of Sports Medicine, 23, 773-775.

Loland, S., Skirstad, B., Waddington, I. (2006). Pain and injury in sport: social and ethical analysis. Routledge, New York.

Longo, U.G., Loppini, M., Berton, A., Marinozzi, A., Maffulli, N., Denaro, V. The FIFA 11+ program is effective in preventing injuries in elite male basketball players: a cluster randomized controlled trial. (2012). American Journal of Sports Medicine, 40, 996-1005.

Montgomery, D.L. (2006). Physiological profile of professional hockey players - a longitudinal comparison. Applied Physiology, Nutrition and Metabolism, 31, 181-185.

Myklebust, G., Engebretsen, L., Braekken, I.H., Skolberg, A., Olsen, O.E., Bahr, R. (2003). Prevention of anterior cruciate ligament injuries in female team handball players: a prospective intervention study over three seasons. Clinical Journal of Sports Medicine, 13, 71-78

Mölsä J., Airaksinen, O., Näsman, O., Torstila, I. (1997). Ice hockey injuries in Finland. A prospective epidemiologic study. American Journal of Sports Medicine, 25, 495-499.

Mölsä, J., Kujala, U., Näsman, O., Lehtipuu, T-P., Airaksinen, O. (2000). Injury profile in ice hockey from the 1970s through the 1990s in Finland. American Journal of Sports Medicine, 28, 322-327.

Mölsä, J., Kujala, U., Myllynen, P., Torstila, I., Airaksinen, O. (2003). Injuries to the upper extremity in ice hockey. Analysis of a series of 760 injuries. American Journal of Sports Medicine, 31, 751-757.

Parkkari, J., Kujala, U., Kannus, P. (2001). Is it possible to prevent sports injuries? Review of controlled clinical trials and recommendations for future work. Sports Medicine,31, 985-995.

Parkkari, J., Kannus, P., Fogelholm, M. (2004). Liikuntavammat - suurin tapaturmaluokka Suomessa. Suomen Lääkärilehti, 41, $3889-3895$.

Parkkari, J., Taanila, H., Suni, J., Mattila, V.M., Ohrankämmen, O., Vuorinen, P., Kannus, P, Pihlajamäki, H. (2011) Neuromuscular training with injury prevention counselling to decrease the risk of acute muscoskeletal injury in young men during military service: a population-based, randomized study. BMC Medicine, 9, 35.

Pasanen, K,, Parkkari, J., Pasanen, M., Hiilloskorpi, H., Mäkinen, T., Järvinen, M., Kannus, P. Neuromuscular training and the risk of leg injuries in female floorball players: cluster randomised controlled study. (2008). British Medical Journal, 1, $337: a 295$. 
Pelletier, R.L., Montelpare, W.J., Stark, R.M. (1993). Intercollegiate ice hockey injuries. A case for uniform definitions and reports. American Journal of Sports Medicine, 21, 78-81.

Pinto, M., Kuhn, J.E., Greenfield, M.L.V.H., Hawkins, R. Prospective analysis of ice hockey injuries at the Junior A level over the course of one season. Clinical Journal of Sports Medicine, 9, 70-74.

Rishiraj, N., Lloyd-Smith, R., Lorenz, T., Niven, B., Michel, M. (2009). University men's ice hockey: rates and risk of injuries over 6years. Journal of Sports Medicine and Physical Fitness, 49, 159-166.

Tator, C.H., Carson, J.D., Edmonds, V.E. (1997). New spinal injuries in hockey. Clinical Journal of Sports Medicine, 7, 17-21.

Tegner, Y. Lorentzon, R. (1991). Ice hockey injuries: incidence, nature and causes. British Journal of Sports Medicine, 25, 87-89.

Tyler, T.F., Nicholas, S.J., Campbell, R.J., Malachy, P.M. (2001). The association of hip strength and flexibility with the incidence of adductor muscle strains in professional ice hockey players. American Journal of Sports Medicine, 29, 123-128.

Tyler, T.F., Nicholas, S.J., Campbell, R.J., Donellan, S., McHugh, M.P. The effectiveness of a preseason exercise program to prevent adductor muscle strains in professional ice hockey players. American Journal of Sports Medicine, 30, 680-683.

Sim, F.H., Simonet, W.T., Melton, L.J., Lehn, T.A. (1987). Ice hockey injuries. American Journal of Sports Medicine, $15,30-40$.

Stuart, M.J., Smith, A.M.. (1995). Injuries in Junior A Ice Hockey. A Three-year prospective study. American Journal of Sports Medicine, 23, 458-461.

Wennberg, R.A., Tator, C.H. (2003). National Hockey League reported concussions, 1986-1987 to 2001-02. Canadian Journal of Neurological Sciences, 30, 206-209. 